\title{
Assessment of strength and deformation of lightweight concrete and its components under triaxial compression, taking into account the macrostructure of the material
}

\author{
Chorikul Raupov*, Ulugbek Shermuxamedov, and Anora Karimova \\ Tashkent State Transport University, Tashkent, Uzbekistan
}

\begin{abstract}
The paper presents the results of experimental studies on the strength and deformations of lightweight concrete, mortar matrix and hardened cement paste under triaxial compression. Tests on samples were carried out using short-term triaxial proportional $\sigma_{1}>\sigma_{2}=\sigma_{3}$ loading (i.e. axial compression + lateral hydrostatic pressure). During the loading, the ratio of the main stresses (both axial and lateral) was kept constant up to the end of tests. The experimental studies were carried out for different low ratios of $\sigma_{2} / \sigma_{1}$. A theoretical estimation has been discussed to approximate experimental results and prediction of triaxial strength values for different types of lightweight concrete. An estimation of the confining pressure parameter $K$ has been done for the used mode of loading.
\end{abstract}

\section{Introduction}

In many cases (tendons anchorage, places of significant stress gradients, columns with spiral reinforcement, etc.), the concrete works under a multiaxial stress state. Based on various criteria, existing failure theories are not always suitable to use in design practice since they are not corresponding to experimental data obtained at different states of stresses. Therefore they require further development and experimental verification. The research results show [1-4], [9-14] that the failure of concrete under triaxial proportional compression (the axial pressure plus lateral hydrostatic pressure) can be of various character, i.e. to be basically of tensile or shear mode depending on the intensity of lateral pressure. The values of lateral pressure intensity factor $K$, obtained by appropriate calculations, also differ from author to author (usually in the range from 8 to 2.7 ) with the sharp increase of this factor at small lateral pressures. The latter fact practically was not mentioned in studies carried out previously.

It is also necessary to note that in many researches, the basic attention was given to assessing strength parameters for various kinds of normal concrete under the combined state of stresses, and very little data are available on deformational behaviour and material's internal structure influence. Lightweight concrete practically has not found reflection in these researches.

*Corresponding author: raupovch@gmail.com 
In this connection, the experimental study on behaviour and strength assessment of lightweight concrete of various structure and its components under triaxial proportional compression (small lateral pressures) was carried out with special emphasis made on the substantiation of factor $K$ specified above.

\section{Methods}

The appropriate tests were carried out to determine the static triaxle strength and deformation characteristics of cylinder specimens of $70 \times 235 \mathrm{~mm}$ (diameter $\times$ height), made from lightweight concrete, mortar matrix and hardened cement paste. Structural characteristics and specification of the materials used for the tested specimens are given in Table 1. Here the abbreviations CL, CM and $\mathrm{CH}$ are used for concrete mixes with low, average and high contents of coarse aggregate, respectively; MM - for mortar specimens representing a matrix of $\mathrm{CM}$ concrete mix; $\mathrm{HCP}$ - for specimens made from cement paste with the $\mathrm{w} / \mathrm{c}$ ratio providing a standard consistence.

Table 1. Structure and characteristics of tested specimens

\begin{tabular}{|c|c|c|c|c|c|c|c|c|c|c|}
\hline \multirow[t]{2}{*}{ Series } & \multicolumn{3}{|c|}{ 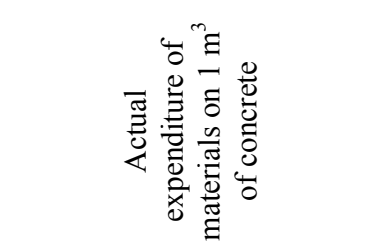 } & \multirow[t]{2}{*}{$W / C$} & & & \multirow{2}{*}{$\frac{\pi}{0}$} & \multirow{2}{*}{$\underset{\Sigma}{\stackrel{\Xi}{\Xi}}$} & \multirow{2}{*}{$\underset{\Sigma}{\Sigma}$} & \multirow{2}{*}{$\stackrel{2}{2}$} \\
\hline & 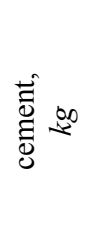 & 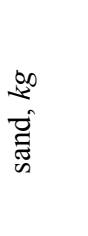 & 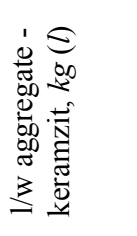 & & 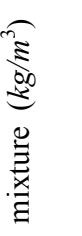 & 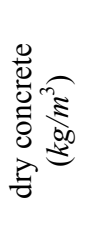 & & & & \\
\hline $\mathrm{CL}$ & 443 & 897 & $284(500)$ & 0.51 & 1980 & 1940 & 19.1 & 36.9 & 32.4 & 0.88 \\
\hline $\mathrm{CM}$ & 429 & 766 & $352(620)$ & 0.50 & 1885 & 1833 & 17.7 & 33.9 & 26.5 & 0.78 \\
\hline $\mathrm{CH}$ & 427 & 629 & $414(727)$ & 0.49 & 1810 & 1760 & 15.4 & 33.0 & 28.4 & 0.86 \\
\hline MM & 669 & 1228 & - & 0.35 & - & - & - & - & - & - \\
\hline $\mathrm{HCP}$ & 1722 & - & - & 0.36 & - & - & - & 45.0 & - & - \\
\hline
\end{tabular}

As a coarse aggregate ceramist (expanded clay) gravel was used in all concrete mixes with two fraction sizes of 5-10 and 10-20 mm at a volume ratio of $40 \% / 60 \%$. To estimate the effect of aggregates on strength values, concrete mixes were designed to have a maximum possible variation in fine and coarse aggregate contents with minimum variations in concrete uniaxial strength values. The samples were cured for 7 months before testing when the strength parameters of the materials are practically stabilized. The slump of a cone for the concrete mixture constituted from 10 to $20 \mathrm{~mm}$. The test set up is shown in Fig. 1. To obtain authentic test results on the material's behaviour at a multiaxial state of stress, it is necessary to have the homogeneous stress distribution along sections of a sample in directions of main working stresses. This causes large difficulties in the elimination of friction over contact surfaces of a sample and the loading device. In large, the elimination of this phenomenon becomes possible by using a principle of the hydrostatic application of loading to a surface of a concrete sample that does not constrain its deformations along the contact zone. 


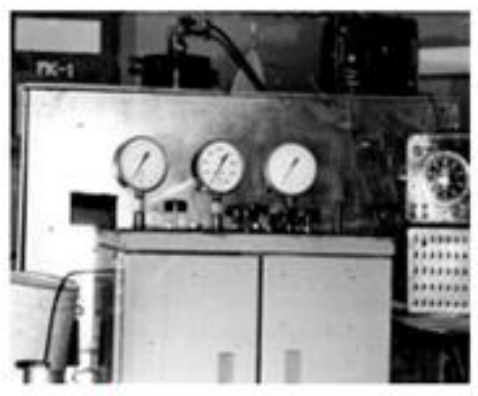

a)

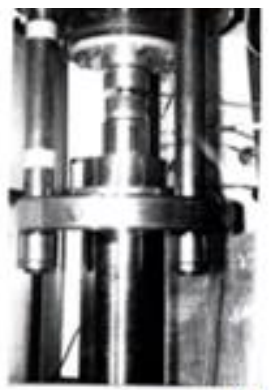

b)

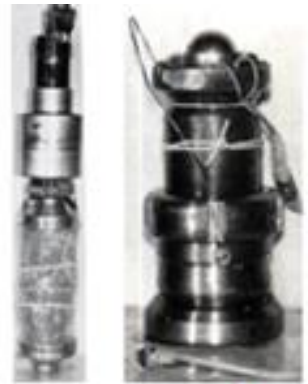

c)
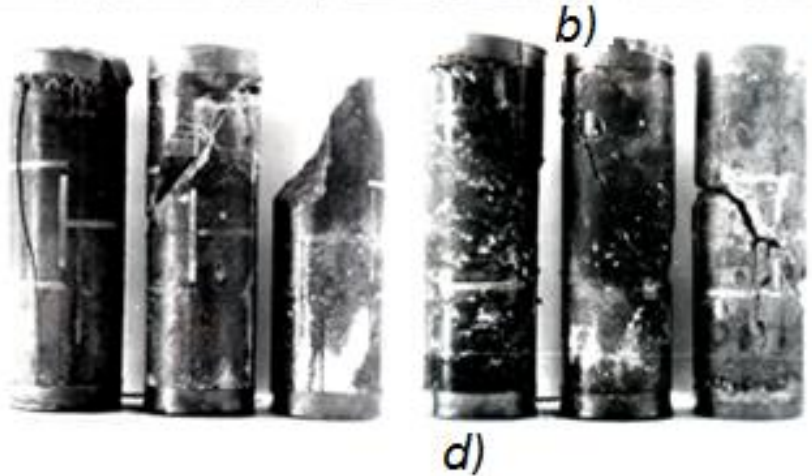

Fig. 1. Test set up for triaxial compression: testing unit (a), installation of specimen (b), spherical hinge (c), specimens after testing (d)

The loading of samples at triaxial hydrostatic compression was carried out in a specially designed testing unit of a "cylinder - piston" type [5], which has allowed to create hydrostatic pressure up to $100 \mathrm{MPa}$ and an axial compression of $1 \mathrm{MN}$. The cylinder of a testing unit has an internal diameter of $110 \mathrm{~mm}$ and a height of $600 \mathrm{~mm}$. The hydraulic pressure in the cylinder was created by the oil pump. Both a spring manometer established on an oil supply and a strain-gauge manometer, placed in the cylinder of a testing unit, was used to measure the pressure. The axial force was induced by a hydraulic jack and measured by a load cell placed between the sample and piston. An axial force to a sample was transferred through spherical hinges and special hydraulic pillows, which provided the homogeneous stress state through the entire volume of a sample. In total 35 electric circuits were provided to the testing unit for the measurements of forces, pressure and deformations.

It is necessary to note the influence of a loading path on strength, especially on a sample's deformation. In the current study, a simple (proportional) loading of samples was carried out when the ratio of the main stresses (both axial and lateral $\sigma_{1}>\sigma_{2}=\sigma_{3}$ ) during the loading was kept constant up to the end of tests. The experimental studies were carried out for cases $\sigma_{2} / \sigma_{1}=0.09 ; 0.13 ; 0.17$; and 0.20 , i.e. on a longitudinal axis loading increments of $\sigma_{1}$ were kept at a larger magnitude, than the lateral pressure $\sigma_{2}=\sigma_{3}$. Shortly before the destruction of samples, at substantial growth of their volumetric deformations, the tendency to increase lateral pressure at a load increments exposure was noticed. 
Table 2. Test results for specimens under triaxial proportional compression

\begin{tabular}{|c|c|c|c|c|c|c|c|c|c|}
\hline $\begin{array}{c}\text { Series } \\
\text { of } \\
\mathbf{m i x}\end{array}$ & $\begin{array}{c}\boldsymbol{\sigma}_{\mathbf{2}} / \\
\boldsymbol{\sigma}_{\mathbf{3}}\end{array}$ & $\begin{array}{c}\boldsymbol{\sigma}_{\mathbf{2}} \\
\boldsymbol{\sigma}_{\mathbf{3}} \\
\mathbf{M P a}\end{array}$ & $\begin{array}{c}\boldsymbol{f}_{\mathbf{c}(\mathbf{3})} \\
\mathbf{M P a}\end{array}$ & $\begin{array}{c}\boldsymbol{f}_{\mathbf{c}(\mathbf{3})}, \\
\mathbf{M P a} \\
\mathbf{F o r m u l a} \\
\mathbf{( 1 )}\end{array}$ & $\begin{array}{c}\boldsymbol{f}_{\mathbf{c}(3)}, \\
\mathbf{M P a} \\
\mathbf{F o r m u l a} \\
\mathbf{( 3 )}\end{array}$ & $\begin{array}{c}\boldsymbol{f}_{\mathbf{c}(3)} / \\
\boldsymbol{f}_{\mathbf{c}}\end{array}$ & $\begin{array}{c}\boldsymbol{\sigma}_{\mathbf{2}} / \\
\boldsymbol{f}_{\mathbf{c}}\end{array}$ & $\boldsymbol{K}$ & $\begin{array}{c}\boldsymbol{K} \\
\text { Formula } \\
(\mathbf{4})\end{array}$ \\
\hline & 0 & 0 & 37.2 & 32.2 & - & 1.00 & 0 & 0 & - \\
& 0.091 & 5.4 & 60.0 & 65.8 & - & 1.61 & 0.16 & 4.22 & - \\
& 0.130 & 9.7 & 74.0 & 78.7 & - & 2.00 & 0.26 & 3.79 & - \\
& 0.167 & 16.0 & 97.5 & 96.1 & - & 2.62 & 0.40 & 3.76 & - \\
& 0.200 & 23.9 & 118.9 & 115.2 & - & 3.20 & 0.64 & 3.42 & - \\
\hline $\mathrm{CM}$ & 0 & 0 & 37.3 & 37.3 & 37.3 & 1.00 & 0 & 0 & 1.00 \\
& 0.091 & 5.4 & 60.4 & 63.7 & 60.0 & 1.62 & 0.14 & 4.27 & 1.61 \\
& 0.130 & 10.2 & 79.2 & 78.5 & 77.2 & 2.13 & 0.27 & 4.12 & 2.07 \\
& 0.167 & 16.0 & 97.4 & 93.8 & 95.7 & 2.62 & 0.40 & 3.76 & 2.57 \\
& 0.200 & 23.8 & 119.1 & 111.9 & 120.1 & 3.20 & 0.64 & 3.44 & 3.22 \\
\hline $\mathrm{CH}$ & 0 & 0 & 37.4 & 37.4 & - & 1.00 & 0 & 0 & - \\
& 0.091 & 5.4 & 60.4 & 63.7 & - & 1.61 & 0.14 & 4.25 & - \\
& 0.130 & 10.1 & 77.1 & 78.6 & - & 2.06 & 0.27 & 3.93 & - \\
& 0.167 & 16.3 & 97.6 & 95.3 & - & 2.61 & 0.43 & 3.69 & - \\
& 0.200 & 22.0 & 114.0 & 109.0 & - & 3.05 & 0.59 & 3.48 & - \\
\hline MM & 0 & 0 & 51.4 & 51.4 & 51.4 & 1.00 & 0 & 0 & 1.00 \\
& 0.091 & 10.0 & 110.0 & 102.2 & 109.9 & 2.14 & 0.19 & 5.86 & 2.13 \\
& 0.130 & 21.0 & 161.0 & 146.8 & 154.9 & 3.13 & 0.41 & 5.22 & 3.01 \\
& 0.167 & 32.0 & 192.0 & 187.8 & 188.4 & 3.79 & 0.62 & 4.39 & 3.68 \\
& 0.200 & 41.8 & 221.8 & 222.6 & 211.5 & 4.31 & 0.81 & 4.08 & 4.11 \\
\hline HCP & 0 & 0 & 98.0 & 98.0 & 98.0 & 1.00 & 0 & 0 & 1.00 \\
& 0.091 & 13.5 & 153.5 & 153.6 & 152.0 & 1.57 & 0.14 & 4.25 & 1.55 \\
& 0.130 & 24.3 & 186.3 & 181.9 & 184.4 & 1.90 & 0.25 & 3.83 & 1.88 \\
& 0.167 & 33.6 & 204.6 & 203.2 & 206.5 & 2.08 & 0.34 & 3.17 & $2 / 11$ \\
& 0.200 & 48.8 & 243.8 & 234.7 & 243.4 & 2.48 & 0.50 & 2.99 & 2.48 \\
\hline
\end{tabular}
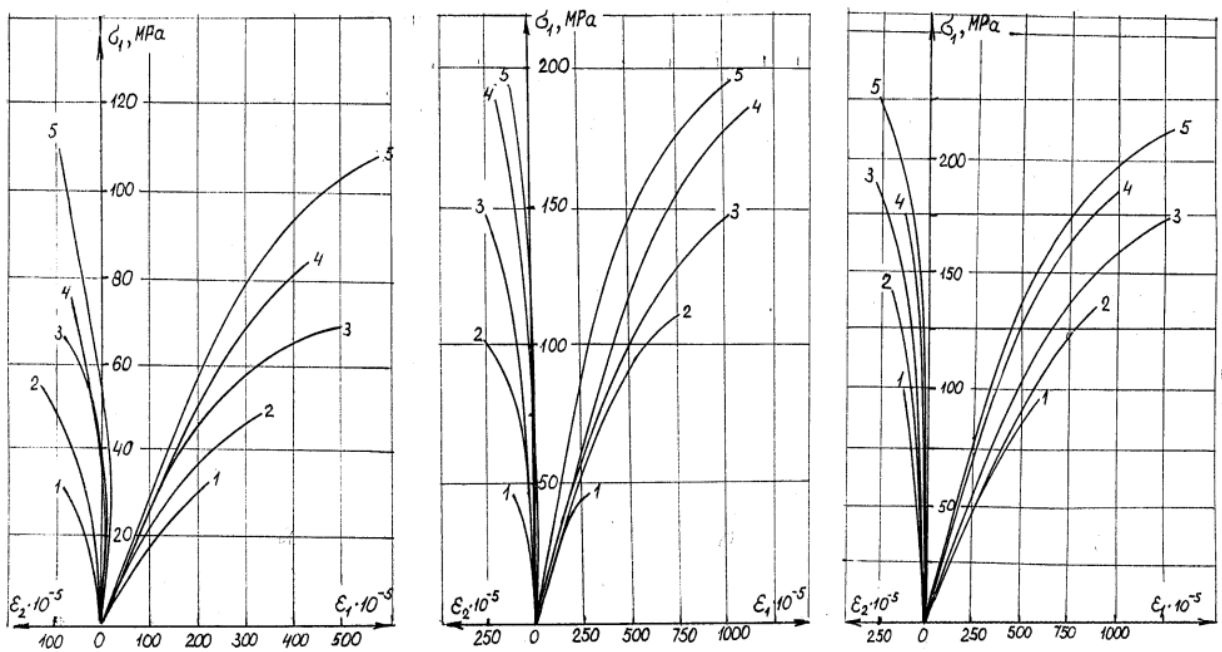

Fig. 2. Stress-strain diagrams for light-weight (mix CM) concrete (a), mortar matrix (b) and cement paste (c) under triaxial compression: 1 is $\sigma_{2} / \sigma_{1}=0 ; 2$ is $\sigma_{2} / \sigma_{1}=0.091 ; 3$ is $\sigma_{2} / \sigma_{1}=0.13 ; 4$ is $\sigma_{2} / \sigma_{1}$ $=0.167 ; 5$ is $\sigma_{2} / \sigma_{1}=0.2$

In this case, lateral pressure reduced down to the given level and was kept practically constant according to the accepted mode of loading. The loading of samples was carried out 
by increments of 0.1 from expected failure loading (approximately of 10-15 increments, each applied for not longer than 5-7 min) until the termination in the growth of short-term creep deformations. Thus, the duration of the test of one sample made approximately 50-80 min. For the measurement of deformations under hydrostatic triaxial compression, the strain gauges were pasted on a 0.2-0.3 mm thick layer of the ground made from glue T-192 and covered with the same layer. Surface pores were closed up by plaster. An entire surface of a sample was again covered with a layer of glue and hydro isolated by sell tape. Test results are shown in Tab. 2 and figure 2. The coefficients of variation of the investigated characteristics do not exceed $15 \%$.

\section{Results and Discussion}

The failure character of samples depended on a level of applied hydrostatic pressure $\left(\sigma_{2} / \sigma_{1}\right)$, as can be seen from Fig. 1 (d). At $\sigma_{2} / \sigma_{1}$ equal to 0.09 and 0.13 , the appearance of failed concrete samples is almost the same as at uniaxial compression, i.e. macro cracks are passing in parallel to the axis $\sigma_{1}$. At $\sigma_{2} / \sigma_{1}=0.167$, failure occurs along an inclined crack, which testifies the shear mode of destruction. At $\sigma_{2} / \sigma_{1}=0.20$, samples after destruction were squashed having a barrel-type form with the obvious signs of buckling, which also testifies about shear or pseudo shear mode of failure. The detailed study of specimen's fragments has shown that even in the latter case, the mechanism of destruction was connected to the development of micro-cracks, which were not of a tensile type, but of shear type mode. The external display of the pseudo-shear character of failure was also observed in mortar samples at $\sigma_{2} / \sigma_{1}=0.167$ and in cement paste samples at $\sigma_{2} / \sigma_{1}=0.20$. Thus, it may be concluded that in the considered type of concrete, even at a higher level of hydrostatic pressure $\left(\sigma_{2} / \sigma_{1}=0.20\right)$ the mechanism of destruction continues to be connected to the development of micro cracks. However, unlike uniaxial compression, these cracks are of shear mode character.

At first approach, the simplest and widely used expression - so-called Considerer's formula - was used and checked for assessment of the concrete triaxial strength, i.e.:

$$
f_{\mathrm{c}(3)}=f_{\mathrm{c}}+K \sigma_{2},
$$

where: $K$ is the factor of lateral pressure intensity.

Using this expression and experimental values of $f_{\mathrm{c}}, f_{\mathrm{c}(3)}$, and $\sigma_{2}$ the values of $K$ for all tested materials (Tab. 2, column 9) were calculated. From the analysis of the diagrams follows, that $K$ is a variable and depends both on material type (i.e., concrete, mortar matrix, and cement paste) and level of lateral confinement. However, the change of the aggregate content in concrete has shown a little effect on values of factor $K$. For each value of $\sigma_{2} / \sigma_{1}$, the scattering in experimental data would overlap a possible influence of changes in the structural composition of lightweight concrete.

Within the investigated range of $\sigma_{2} / \sigma_{1}$, the values of $K$ obtained during the test were in the range from 3 to 4 for lightweight concrete and from 4 to 6 for cement paste. Thus, it may be concluded that only when the standard referred data on $K$ is available for various types of concrete and various values of $\sigma_{2} / \sigma_{1}$, the eq. (1) may be used directly to define the $K$ without carrying triaxial tests. So far, as can be seen from the test results, the values of $K$ are not affected by the content of coarse aggregate (which ranged from $29 \%$ up to $42 \%$ ). In that case, its values may be accepted according to Table 3 .

Table 3. Test results coefficient value $K$

\begin{tabular}{|c|c|c|c|c|c|}
\hline$\sigma_{\mathbf{2}} / \boldsymbol{\sigma}_{\mathbf{1}}$ & 0 & 0.09 & 0.013 & 0.017 & 0.20 \\
\hline$K$ & 0 & 4.25 & 3.95 & 3.75 & 3.45 \\
\hline
\end{tabular}


B. Hobbs [5] studied the influence of concrete structure and maturity on triaxial strength and proposed the following empirical expression to approximate available data on triaxial tests:

$$
f_{\mathrm{c}(3)}=f_{\mathrm{c}}+A \sigma^{\mathrm{B}}{ }_{2},
$$

where $A$ and $B$ are partial coefficients to be specified for each particular type of specimen tested: $A$ takes account of concrete type, and $B$ allows for uniaxial strength and structure of concrete as a function, $\psi\left(f_{c} ; V_{\text {fine ag. }} / V_{\text {coarse ag. }}\right)$.

For general purposes the coefficient $A$ can be described by the equation proposed in [6] as follows:

$$
A=C+\left[\frac{D}{\left(V_{\text {fine.ag. }} / V_{\text {coarse.ag. }}\right)-E}\right]+H \times f_{\mathrm{c},}
$$

where $A, C, D$, and $E$ are empirical coefficients.

All coefficients were calculated using the list square method and are equal to $0.07 ; 6.57$;

0.11 , and 1.05 , respectively. The part of the formula in brackets reflects the influence of $V_{\text {fine ag. }} / V_{\text {coarse ag. }}$ for each fixed value of $f_{\mathrm{c}}, H$ depends on $f_{\mathrm{c}}, \mathrm{C}, \mathrm{D}$, and $\mathrm{E}$ reflect the influence of concrete structure.

Therefore, using eq. (3) the eqs. (2) can be modified in the following form:

$$
f_{\mathrm{c}(3)}=f_{\mathrm{c}}+\left\{C+\left[\frac{D}{\left(V_{\text {fine.ag. }} / V_{\text {coarse.ag. }}\right)-E}\right]+H \times f_{\mathrm{c}}(28)\right\} \sigma^{\mathrm{B}}{ }_{2}
$$

This equation was used to approximate the values of $f_{\mathrm{c}(3)}$ obtained in the current study (see Tab. 2, column 10) using the values of the coefficient $B=0.7$ for concrete and cement paste and $B=0.85$ for mortar matrix. The results were plotted in graphs produced in Fig. 3 . Curves of absolute and relative values of ultimate strength at triaxial compression depending on $\sigma_{2} / \sigma_{1}$ are given in Fig. 3(a). Fig. 2(b) shows the lines of intersection of a concrete failure surface with $\sigma_{2} / f_{c}-\sigma_{1} / f_{c}$ plane. The comparison of these curves for lightweight concrete shows that at practically identical values of cylinder strength and identical levels of lateral pressure $\sigma_{2} / \sigma_{1}$, the triaxial compression strength, $f_{\mathrm{c}}$ practically does not depend on the structure of concrete. The relative strengthening for lightweight concrete during the growth of lateral confinement goes less intensively than for mortar matrix and cement paste.

In general, the shape of strengthening curves for cement paste and mortar specimens show that this process is quite complex. Their nonlinear character with contra flexures can be considered as a reflection of the presence of various macro structural defects, the influence of which on ultimate compression strength is compensated accordingly by a confining pressure of various intensity. The same approach in the assessment of the influence of hydrostatic pressure is given in [7, 8]. It is visible from Fig.3 that the curves obtained for all three lightweight concrete mixes practically coincide and can be described by the same equation. 

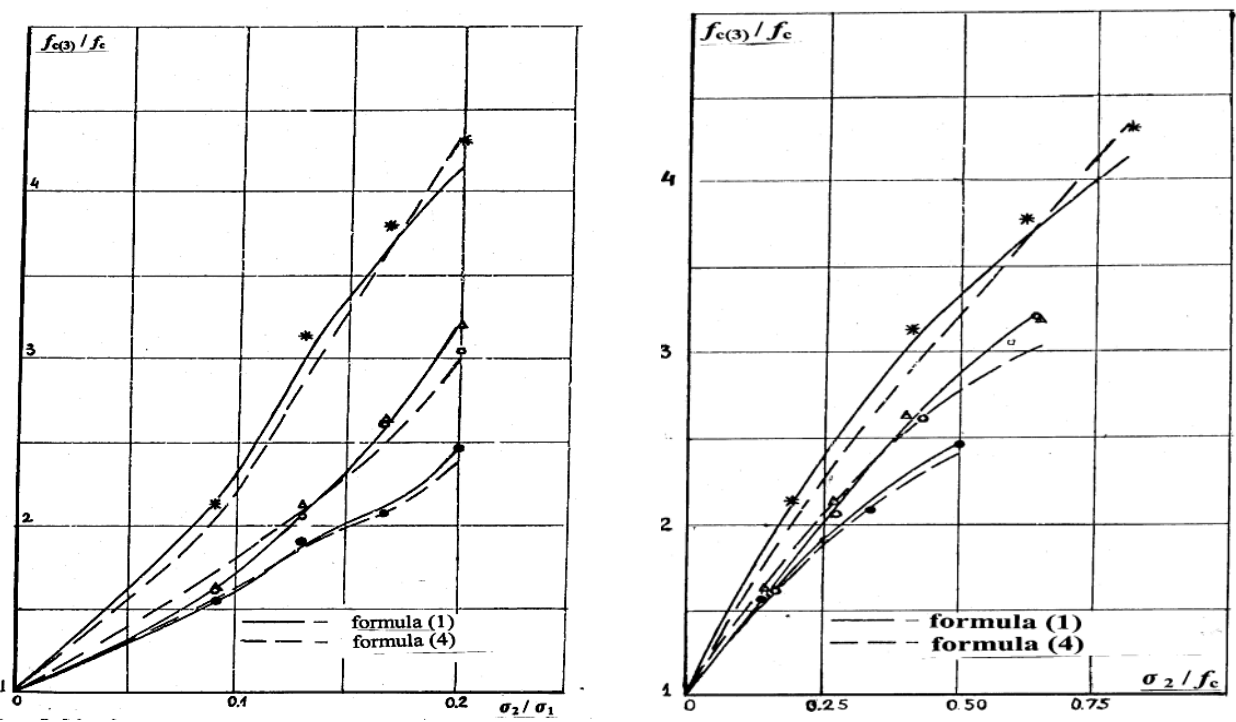

Fig. 3. Relation between axial and lateral pressure at failure for different specimens: $\odot-C L ; \Delta-C M$; 口- $\mathrm{CH} ;-\mathrm{MM} ; \bullet-\mathrm{HCP}$

During the growth of hydrostatic pressure, an identical relative strengthening of lightweight concrete with different contents of coarse aggregate may be explained by the fact that at given lateral confinement, the strengthening of the lightweight concrete occurs only at the expense of strengthening of a mortar matrix. Thus, it is possible to make a conclusion that the destruction of the lightweight concrete at volumetric compression begins and proceeds into a mortar matrix. It proves to be true also by the fact that at uniaxial compression, the strength of all three mixes is also practically equal (see Tab.1). This conclusion makes it possible to extend the use of the mathematical model for normal concrete developed elsewhere [8] on lightweight concrete both at uniaxial and triaxial compression. The model considers the failure and deformation of concrete as the process of micro- and macro cracks development in a matrix, with the only peculiarity, which in lightweight concrete the role of cracks in contact zone is reduced to a minimum at the expense of good bondage of a matrix with aggregate particles.

\section{Conclusions}

It may be concluded that new test data has been acquired on compression strength and deformations for lightweight concrete and its constituents under short-term triaxial proportional $\sigma_{1}>\sigma_{2}=\sigma_{3}$ loading (i.e. axial compression + lateral hydrostatic pressure).

It is confirmed that triaxial strength is highly dependant on values of lateral confining pressure. An estimation of the confining pressure parameter $K$ has been done for the used mode of loading. At low values of $\sigma_{2} / \sigma_{1}$ ranging from 0.09 to 0.2 , the factor $K$ for lightweight concrete changes from 3 to 4 .

It is established that for particularly specified uniaxial strength of lightweight concrete, its strength at triaxial proportional compression is not significantly affected by parameters of inner structure, with the increase of coarse lightweight aggregate content (from $29 \%$ up to $42 \%$ ) the triaxial strength remained practically constant.

The proposed eq. (4) with sufficient accuracy (not exceeding 5\%) approximates experimental data and can be used to predict triaxial strength values for lightweight concrete. 


\section{References}

1. Luksha, L.K., Strength of concrete under confinement. Concrete and reinforced concrete. №1, (1973)

2. The deformations and the rapture of solids subjected to multiaxial stress. Colloquia International Cannes, 4 - 6 Oct., (1972)

3. Berg, O.Ya., Solomentsev, G. G. Study on stress-strain state of concrete at triaxial compression. NIISK - "Studies on deformations of structures", Transport, Moscow, (1969)

4. Malashkin Yu.,N., Ish, V.G., Tyablikov, B.V., Bezgodov, I.M. Studies on strength and deformations of concrete with respect to the type of stressing. Coordin. Sem. on Hydrotech. № 99, (1975)

5. Girenkov, A.N., Krasnovsky, R.O., Krol, I.S. Metrological study on testing unit for concrete under volumetric state of stress. Collection of research works of VNIIFTRI, Moscow, (1983), pp. 82-87.

6. Tyablikov, B.V. Strength and deformations of concrete in massive structures at nonuniaxial compression. $\mathrm{PhD}$ thesis, Moscow, 1984, $236 \mathrm{pp}$.

7. Berg, O. Y., Scherbakov, E. N., Pisanko, G. N. High strength concrete. 'Stroyisdat', - Moscow, (1982), p. 208

8. Ashrabov, A.A., Zaytsev, Y.V. Elements of fracture mechanics of concrete. "Ukituvchi"- Tashkent, (1982), p. 238

9. Anvar, A., Shaumarov, S., Elena, S., Ulugbek, S. New method for diagnostic of heat engineering and mechanical properties of cellular concrete // International Journal of Engineering and Advanced Technology, 9 (1), pp. 6885-6887, (2019)

10. Ishanovich, A.A., Vladimirovna, S.E., Sanatovich, S.S., Zabihullaevich, S.U., Ishratovich, K.S. Some aspects of the photo-optical method of estimation composition of light concrete // International Journal of Engineering and Advanced Technology, 8(5), pp. 1924-1927, (2019)

11. Adilkhodjaev, A., Shaumarov, S., Kadir, U. New structure assessment method cell concrete // International Journal of Advanced Science and Technology, 29(5), pp. 1889-1893, (2020)

12. U. Shermuxamedov, S.Salixanov, S.Shaumarov, F.Zokirov. Method of selecting optimal parameters of seismic-proof bearing parts of bridges and overpasses on highspeed railway lines // European Journal of Molecular \& Clinical Medicine, ISSN 2515-8260, 7(2), pp. 1076-1084, (2020)

13. U.Z. Shermukhamedov, T.R. Rashidov. Features of the theory of a two-mass system with a rigidly connected end of the bridge, in consideration of seismic influence on high-speed railways // European Journal of Molecular \& Clinical Medicine, ISSN 2515-8260, 7(2), pp. 1160-1166, (2020)

14. Bekmirzaev D.A., Kishanov R.U., and Mansurova N.S. Mathematical Simulation and Solution of the Problem of Seismo-Dynamics of Underground Pipelines Int. J. Emerg. Trends Eng. Res. 8 5028-5033. (2020) 